Fundamentos de la Teoría general. Las consecuencias teóricas de Lord Keynes

Axel Kicillof

2008. Buenos Aires. Eudeba.

Al economista Axel Kicillof (25-091971) se le atribuye la redacción del proyecto de ley de expropiación del $51 \%$ de las acciones de YPF en manos de Repsol que Cristina Fernández de Kirchner envió al Congreso en abril de 2012. Kicillof se graduó con diploma de honor en la Facultad de Económicas de la Universidad de Buenos Aires (UBA). En 1992 fundó la asociación estudiantil TNT (Tontos pero No Tanto) y, en los últimos años, ingresó en la agrupación política juvenil La Cámpora. En 2004 fundó, junto con otros economistas, el Centro de Estudios para el Desarrollo Argentino (CENDA). A sus 41 años ha sido autor de tres libros y de cerca de cincuenta artículos y documentos de trabajo. Doctor en Economía por la Universi- dad de Buenos Aires, desde principios de 2011 tiene una licencia sin goce de sueldo como docente e investigador, otorgada por la UBA y el Consejo Nacional de Investigaciones Científicas y Técnicas (CONICET), para desempeñar primero el cargo de subgerente general de la estatal Aerolíneas Argentinas Austral y después el de secretario de Política Económica y Planificación del Desarrollo del Ministerio de Economía y Finanzas Públicas.

El objetivo principal de Kicillof en su tesis doctoral - publicada como libro y comentada en estas páginasfue arrojar luz sobre los fundamentos propuestos por Keynes. Se trata de una tesis producto de una investigación desarrollada entre finales de 1998 y principios de 2005, en el marco de la Universidad de Buenos Aires. Según el propio Kicillof, los interrogantes que le dieron vida surgieron durante sus años de formación como economista: por un lado, la carrera de economía estaba basada en libros de texto y pa- 
pers inscritos en su mayoría en la síntesis neoclásica; por otro lado, toda su actividad «extracurricular» conducía hacia las obras clásicas de Smith, Ricardo y, especialmente, Marx, autores prácticamente ausentes en las teorías ortodoxas o neoclásicas. Kicillof explica: «encontrar que Keynes entablaba en su Teoría general un diálogo frontal con las preocupaciones de los autores clásicos fue para mí un descubrimiento liberador. A contramano del relato metabolizado por la síntesis, el economista más importante del siglo $\mathrm{xx}$ ofrecía su propia perspectiva acerca de los fundamentos de la economía: la teoría del capital, la teoría del dinero y la teoría de la mercancía. Se revelaba así, ante mí, una verdad olvidada: detrás de la infinidad de modelos fragmentarios que pueblan los programas de estudio de la economía tradicional, se encuentran ocultas, en un submundo actualmente inexplorado, sus propias explicaciones últimas acerca del origen del valor y del excedente. Hay, pues, otra economía detrás de la economía. Este trabajo se convirtió así, durante su propio desarrollo, en lo que hoy es: un ajuste de cuentas con la formación que me ofreció la economía mainstream».

En 1936 John Maynard Keynes publicó su Teoría general de la ocupación, el interés y el dinero, obra que lo convirtió en el economista más influyente del siglo xx. Kicillof destaca que su nombre aún sigue ligado férreamente a las políticas económicas expansi- vas $y$, en general, a todo avance de la intervención del Estado en los asuntos económicos.

Si bien el tipo de políticas públicas que Keynes defendió era frecuente en la década de 1930, sus teorías representaron un esfuerzo consciente por retratar los cambios profundos que modificaron el Estado y el sistema capitalista a principios del siglo xx. Así pues, para Kicillof, la Teoría general es la manifestación de una crisis en la teoría económica ortodoxa en el marco de la crisis más grande del capitalismo. Keynes creía que esta teoría había sido concebida para una etapa histórica ya pasada, razón por la que sus enseñanzas eran engañosas, $y$ negativas si se intentaban aplicar a la realidad. En palabras de Kicillof, «cuando llegó el turno de lidiar con la inflación de posguerra, como cuando, poco después, sobrevino la depresión, la ortodoxia defendió y pretendió aplicar - y lo hizo en muchos casos - las tradicionales políticas contractivas, encaminadas a reducir el gasto público, a restringir el crédito y la liquidez y a presionar para que se produjera una reducción generalizada de los salarios. Tanto en un contexto de inflación como en uno de alta desocupación, la contracción es la panacea de la ortodoxia, porque supone que cuando el mercado actúa por sí mismo es infalible; de modo que la respuesta consiste en evitar toda intromisión en sus mecanismos [por parte del Estado y de los trabajadores organizados]». 
No obstante, mientras la figura de Keynes adquiría un enorme protagonismo en la economía, en la política y en el debate público, la Teoría general se perdía en el olvido. Y lo paradójico para Kicillof está en que fueron los propios seguidores de Keynes, desde un principio y hasta ahora, quienes llegaron al sorprendente consenso de que la Teoría general no solo está mal escrita y es confusa, sino que, además, su argumento considerado como un todo es inconsistente. $\mathrm{Y}$ peor aún, la obra fue sometida a un proceso de «apropiación selectiva»: algunas de sus ideas fueron absorbidas por la teoría económica, pero otras, en cambio, fueron desechadas sin ser siquiera sometidas a crítica.

Según Kicillof, el principal reproche que puede hacerse a los detractores (pero también a los seguidores) de Keynes es que no intentaron reconstruir el argumento completo de la Teoría general, una tarea que debe preceder a toda intención crítica. Además, muestra que el objetivo expresado por Keynes en su obra consistió en hacer compatibles la teoría del valor y la teoría del dinero, alcanzando así la representación de una economía monetaria. Cuando el atribulado mainstream se enfrentó a la Teoría general, se inclinó por adoptar solo el «modelo» que Keynes ofrecía, pero despreció sus fundamentos teóricos, y por ello tuvo que pagar el alto costo de dividir la teoría económica en dos ramas inconexas: la microeconomía y la macroeconomía. En el campo de la primera se conservaron los viejos fundamentos del marginalismo aportados fundamentalmente por Marshall y Walras, mientras que la macroeconomía se acostumbró a construir sus modelos sin discutir los conceptos de dinero, capital y valor. Para Kicillof «esta separación, ahora naturalizada, es ajena al pensamiento de Smith y Ricardo, pero también al de los fundadores del marginalismo; solo cobró cuerpo luego de la embestida de Keynes». A partir de ese momento comenzó a tomar forma la llamada síntesis neoclásica, con el objetivo de ocultar y posponer la crisis teórica keynesiana sin resolverla. Así pues, la crítica de Keynes «estuvo dirigida hacia las ideas centrales del mainstream de su época, ideas que, en lo fundamental, eran idénticas a las que sostiene aún hoy la teoría microeconómica». El saldo más significativo de la llamada síntesis neoclásica es, para Kicillof, que ninguno de sus dos compartimientos se reservó un lugar para discutir los fundamentos teóricos, esto es, la naturaleza misma de las categorías económicas. Ni la microeconomía ni la macroeconomía se han ocupado de la naturaleza del dinero y del capital, del origen del interés y de la ganancia, de la teoría del valor y de las determinaciones históricas del capitalismo.

En su libro, Kicillof mostró que Keynes, con la Teoría general, no se proponía fundar la macroeconomía como una rama nueva en el marco de la teoría económica, sino denunciar las 
fallas históricas, lógicas y empíricas de la teoría neoclásica y reemplazar sus fundamentos teóricos sobre el valor, el dinero y el capital. Desde su punto de vista, a pesar de que Keynes no encontró una respuesta adecuada a los interrogantes que intentó responder, su crítica a la economía neoclásica no ha perdido nada de su profundidad y vigencia en el presente. Por todo ello, Kicillof se propuso demostrar que la contribución más importante de la Teoría general no se reduce al «modelo» que propone para determinar el nivel de empleo, sino que está contenida en otros dos aspectos: su agudísima crítica a la teoría ortodoxa y la búsqueda de unos fundamentos teóricos distintos de los ofrecidos por ella. Y, si bien en su libro Kicillof no defiende las conclusiones a las que llega la Teoría general, sostiene que es necesario volver a discutir los fundamentos mismos de la teoría económica, y que en ese debate Keynes tiene algo que decir.

De este modo, podemos plantear que la metamorfosis a la que fueron sometidas las ideas originales de Keynes dejó de lado un conjunto de elementos centrales que son imprescindibles para comprender algunas causas de la crisis actual, diseñar políticas para impulsar la actividad económica y regular los mercados financieros. Una de esas ideas esenciales de Keynes es la de que el nivel de actividad está determinado por el gasto, por la demanda efectiva. Keynes invirtió la causalidad vigen- te en las teorías ortodoxas otorgando un lugar predominante a la demanda efectiva. Según planteó, para impulsar el nivel de actividad se requiere inversión y gasto público y privado. A pesar de la fortaleza lógica y empírica de ese razonamiento, la visión de Keynes fue abandonada. En su reemplazo se estableció la reducción del déficit fiscal mediante el ajuste como mecanismo para reactivar la actividad económica.

Ante todo, la pregunta no es si los estados deben intervenir o no en la economía, ya que los mercados no existen por sí solos; siempre existen en un contexto de reglas, leyes, regulaciones y políticas públicas. Por tanto, el neoliberalismo no defiende un estado ausente, sino uno que intervenga activamente para desregular, flexibilizar el mercado laboral, privatizar y subsidiar a los sectores concentrados. Por otro lado, la reciente aplicación de políticas neoliberales en los países europeos nos ha demostrado que estas no son patrimonio exclusivo de la derecha. De hecho, la ortodoxia se ha convertido en una trampa para los partidos socialdemócratas, que han carecido de voluntad política para sostener su histórica agenda progresista y por ello han sido desalojados del poder.

Los estímulos desplegados hoy por Estados Unidos no son suficientes para reactivar los niveles de actividad, y los ajustes aplicados en Europa recuerdan los implantados durante los años noventa en América Latina, también 
producto de políticas neoliberales en un marco de crisis de deudas soberanas. En ese contexto, que desencadenó la crisis económica y social, Argentina declaró el cese de pagos más grande de la era moderna en 2001. El gobierno kirchnerista, en el poder desde 2003, concertó un exitoso canje de deuda por el porcentaje de quita de capital, la extensión del plazo de pago y la baja de la tasa de interés de los bonos que reemplazaron a los del default. Se consiguió además una aceptación muy elevada de la propuesta del trueque de papeles, que alcanzó el 93\% del total de acreedores en dos operaciones, realizadas en 2005 y 2010. A partir del cierre del primer canje, el kirchnerismo se ha convertido en el período político que más deuda ha pagado en forma neta desde el regreso de la democracia en 1983. Argentina abandonó el tipo de cambio fijo y reestructuró su deuda, lo que le permitió salir de la crisis y retomar la senda del crecimiento.

Uno de los grandes mitos que se repiten permanentemente en gran parte de las corporaciones mediáticas nacionales e internacionales es que el rápido crecimiento de la economía argentina durante la última década se ha debido a un auge de la exportación de commodities. Tal y como destacan economistas como Paul Krugman o Mark Weisbrot, en la prensa internacional predominan los artículos que hablan en un tono muy negativo sobre la situación actual de Argentina. La reali- dad es que su expansión económica se debió a la inversión y al consumo internos, producto de cambios fundamentales en sus decisiones macroeconómicas y de políticas de redistribución del ingreso. Es decir, la estrategia exitosa seguida por Argentina poco tiene que ver con el «viento de cola» de la exportación de las commodities propias de los sectores concentrados que defienden el modelo sojero a ultranza. Y menos aún tiene que ver con los planes de austeridad impuestos a los países periféricos en Europa.

A finales de 2011, luego de la reelección de Cristina Fernández de Kirchner, Kicillof desembarcó en el Ministerio de Economía junto con otros economistas graduados en la UBA, como Emmanuel Álvarez Agis, Nicolás Arceo y Javier Rodríguez. A los pocos meses se activó una campaña mediática en su contra en artículos de prensa como el titulado «Axel Kicillof, el marxista que desplazó a Boudou» (La Nación, 12/03/2012), cuyo autor, Carlos Pagni, sostiene premeditada y falazmente que «en los últimos tiempos Kicillof se concentró más en Marx. Está aprendiendo alemán para leerlo en su versión original. Hijo de un psicoanalista, bisnieto de un legendario rabino llegado de Odessa, la genealogía de Kicillof parece ser una sucesión de dogmáticas». Punto por punto, estas calumnias de tipo macartista y antisemita fueron desmontadas por el aludido. Desde entonces el relato 
mediático opera para generar disputas internas y conflictos entre diversos funcionarios oficialistas, con el objetivo de desgastar la imagen del gobierno. Además, el proceso de formación de un equipo económico heterodoxo que planifique el desarrollo es presentado por los medios hegemónicos argentinos con titulares del tipo «Los apóstoles de Kicillof, los antiguos amigos y los números de las eléctricas» (Clarín, 04/05/2012).

La realidad es que en enero de 2012 se reestructuró el organigrama del Ministerio de Economía. Con ello, se dispuso el traspaso del área de la que dependen los directores del Estado que participan en la conducción de las empresas privadas, como es el caso de Kicillof en Siderar. En total, el Estado tiene participación en unas cuarenta firmas coordinadas por la Dirección de Gestión Empresaria, que pasó a depender de la Subsecretaría de Coordinación Económica y Mejora de la Competitividad.

En calidad de viceministro de Economía y secretario de Política Económica, Kicillof presentó el pasado mes de septiembre de 2012 en el Congreso los principales lineamientos macroeconómicos del proyecto de Presupuesto 2013. Primero enmarcó el debate en un recorrido histórico partiendo de la última dictadura militar, periodo que dio inicio al neoliberalismo en Argentina y al que siguieron la década menemista y los dos años de la Alianza.
Siguiendo este derrotero, sostuvo que en 2003 se inició una nueva etapa de industrialización del país, donde el Estado pasó a desempeñar un papel clave en la economía. Y aseguró que para sostener la economía hay que poner el gasto público al servicio de la producción y del empleo.

En un encuentro en el Ministerio de Trabajo sobre formación laboral y competitividad donde participaron cámaras empresarias y sindicatos, Kicillof aseveró: «no les vamos a dar el gusto de aplicar las recetas de ajuste; el camino para lograr mejoras genuinas de competitividad es más difícil, requiere más Estado, mejores salarios, capacitación, diálogo y planificación (...). El cambio estructural es un proceso a largo plazo. Para que la reindustrialización sea exitosa va a tomar más tiempo que los 30 años que duró la política neoliberal iniciada en 1976» (Página 12, 9/11/2012). «No quieren que nos industrialicemos, quieren que Argentina sea un paraíso financiero y agroexportador», apuntó el secretario de Política Económica, quien aprovechó su intervención para cuestionar «la política de privatización de servicios públicos con tarifas altas», así como «la falta de inversión privada en materia energética». Kicillof explicó que las recetas de industrialización ortodoxas para los países periféricos como Argentina exigen «industrias poco calificadas, bajos salarios, malas condiciones laborales, el impedimento 
de la sindicalización para eliminar los conflictos y megadevaluaciones de la moneda (...). Aplicar las políticas neoliberales de industrialización es muy sencillo, pero sería una derrota para nuestro proyecto y no les vamos a dar el gusto», aseveró.

Las experiencias traumáticas de las fases recesivas en el ciclo económico argentino predisponen a creer que toda crisis concluirá necesariamente en resultados devastadores. Los antecedentes de varias décadas ofrecen como prueba fuertes devaluaciones de la moneda nacional, incremento de la desocupación, quiebra de empresas y bancos, deterioro social y fuerte aumento de la pobreza. Uno de los aspectos más destacados del actual ciclo económico es que la crisis de 2009 y la de 2012 no han tenido la resolución prevista teniendo en cuenta las precedentes: se ha comprobado que existe otra manera de atravesar el proceso recesivo de la economía amortiguando sus efectos y no profundizándolos. El actual contexto económico internacional ha sido una señal contundente para rectificar el rumbo en el frente fiscal, que exige expansión en la fase negativa del ciclo económico. La mayor financiación del Banco Central al Tesoro dentro de los límites establecidos por la nueva Carta Orgánica es la medida adecuada para retornar el aliento a la demanda agregada eludiendo las políticas de ajuste.

La economía estaba caminando hacia el abismo de la restricción ex- terna, por el tipo de crecimiento en los últimos años, con una fuerte alza de las importaciones, desequilibrio de la balanza comercial energética, acelerada fuga de capitales y excedentes de producción de las potencias presionando sobre el mercado local. Una fuerte devaluación con el consiguiente shock inflacionario ha sido históricamente la respuesta a la escasez estructural de divisas. El gobierno se propuso desafiar ese desenlace, que hubiera venido acompañado de elevados costos sociales y políticos, mediante un estricto régimen de administración del comercio exterior y de divisas. Esa fue la estrategia elegida para eludir la restricción externa por estrangulamiento de divisas en la balanza de pagos.

Por otro lado, la decisión del gobierno argentino de expropiar el 51\% de YPF en abril de 2012 ha permitido recuperar el manejo estratégico de la petrolera para lograr el autoabastecimiento energético. Así, se está revocando una política neoliberal de los años noventa enormemente negativa para el país, a pesar de que recientemente Repsol ha demandado al Estado argentino en el Centro Internacional de Arreglo de Diferencias Relativas a Inversiones del Banco Mundial (CIADI). Luego de la expropiación de YPF, Kicillof fue designado viceinterventor de la compañía, y ha sido objeto de una campaña mediática en España, que podemos ejemplificar con los artículos de prensa «Axel Kicillof, el seductor 
intelectual de Cristina Kirchner» (El Mundo, 15/04/2012), «Irreverente, pero no tanto» (El País, 19/04/2012) $y$ «El planificador del saqueo» $(A B C$, 17/04/2012). En ellas se subraya el acceso directo que, presuntamente, tiene a la presidenta, y su supuesto perfil radical, dogmático y oportunista.

Es interesante destacar que, a tres años de la estatización de Aerolíneas Argentinas de manos del Grupo Marsans, en la que Kicillof fue también viceinterventor, se informa en los medios españoles e internacionales el procesamiento de Gerardo Díaz Ferrán: el juez de la Audiencia Nacional de España ha decretado el ingreso en prisión eludible bajo fianza de 30 millones de euros para el expresidente de la CEOE por el supuesto vaciamiento patrimonial del Grupo Marsans para evitar el pago a sus acreedores.

Más allá de ello, la recuperación de YPF fue una decisión estratégica, ya que se apostó por un plan para garantizar el autoabastecimiento energético, incrementar los proveedores locales y alcanzar una mayor sustitución de importaciones como eje central de las políticas públicas nacionales. Asimismo, recientemente se creó la empresa YPF Tecnológica $\mathrm{S}$. A., un proyecto del que participan el Ministerio de Ciencia, Tecnología e Innovación Productiva y el CONICET, que nace con el objetivo de impulsar la formación de recursos humanos que puedan aportar su conocimiento al desarrollo de la industria de los hidrocarburos. De manera complementaria, recientemente la Comisión Nacional de Valores está evaluando alternativas de inversión, como la suscripción en bancos del nuevo bono de YPF para pequeños ahorristas, con un monto mínimo de mil pesos y una tasa de retribución del 19\%. Se espera que sea una opción más rentable que atesorar en dólares.

En 2012 el gobierno argentino también convirtió en ley la nueva Carta Orgánica del Banco Central, lo que permitió revocar las reglas de la convertibilidad y ampliar el mandato de la institución para perseguir objetivos múltiples. Estos objetivos incluyen el crecimiento, una distribución del ingreso más equitativa, la promoción del crédito sectorial y la estabilidad de precios. Con ello se propone la reconstrucción de una banca central que evoca la experiencia argentina de los noventa y la europea actual. En el largo periodo en que predominó la ortodoxia en el Banco Central fue cuando más descalabros se registraron en el sistema monetario y bancario. Desde 1976, cuando la dictadura liberalizó el mercado financiero y el Banco Central quedó en manos de los liberales, se sucedieron crisis bancarias, estafas a ahorristas, estatización de la deuda externa privada, estallidos inflacionarios y cambios de moneda. En la Argentina de los años 90, la política económica operó bajo la carga de una forma extrema de ese diseño limitado, un régimen de caja de conversión 
con un tipo de cambio fijado al dólar y una base monetaria estrictamente vinculada con la evolución de las reservas internacionales. Entre 1997 y 2002, la debilidad inherente a esta política monetaria generó un colapso económico $y$ alta inflación. No obstante, el diseño neoliberal de los bancos centrales exige que persigan como objetivo exclusivo una meta de inflación, y el único instrumento disponible para lograrlo es la tasa de interés.

Con la nueva Carta Orgánica del Banco Central y su accionamiento de los últimos años se impide que la especulación privada del dólar afecte a su nivel de reservas. La experiencia argentina indica que el Banco Central debe tener una importante cantidad de reservas internacionales como dique defensivo a los intentos de instalar un escenario de incertidumbre y gobiernos frágiles, y para enfrentar con éxito corridas cambiarias. La administración de divisas y los consiguientes controles para comprar dólares de los últimos meses pusieron fin a un aceitado mecanismo que favorecía y facilitaba la compra de dólares y la fuga de capitales, y que incluía una participación directa de grandes bancos locales e internacionales.

La fiscalización de las operaciones con dólares es una herramienta necesaria para disminuir la evasión y combatir el lavado de dinero, $y$ forma parte de una política de administración de divisas. El mercado muy liberal de ac- ceso a moneda extranjera no era equitativo para la sociedad en su conjunto. La regulación del mercado de divisas fue una respuesta de emergencia ante la intensidad de la fuga de capitales; el mecanismo de control y administración de divisas fue el recurso para evitar que unos pocos acumularan una ganancia de capital por una fuerte devaluación con costos para el resto. Esta mayor regulación pudo instrumentarse gracias a la previa recuperación de márgenes de autonomía en la política económica y monetaria. De todos modos, la restricción externa por el déficit de divisas se acercó peligrosamente, y es sabido que se trata de uno de los eslabones débiles de la economía argentina, cuyo desenlace no puede ser otro que la crisis, con una fuerte devaluación e inflación posterior, acompañada de inestabilidad política y social. El objetivo del régimen de compra de moneda extranjera fue evitar este escenario, sabiendo que las alternativas eran una fuerte devaluación, el ajuste fiscal o el endeudamiento a tasas de interés muy altas. Todas opciones más perjudiciales para la economía y para los sectores vulnerables-incluso para la clase media- que un régimen de administración de divisas.

A estas políticas se suma el proyecto de ley que abre la posibilidad de operar en el mercado de capitales y termina con su autocontrol. En línea con la tendencia internacional posterior a la crisis de 2008, se modificará el ac- 
tual mercado de capitales, que funciona como un club cerrado que se autorregula, autocontrola y autosanciona, $y$ que no ha logrado el objetivo de convertirse en un canalizador del ahorro para el desarrollo, sino que ha privilegiado los componentes especulativos. Esta iniciativa, que ha despertado duras críticas por parte de algunos sectores empresariales, otorga mayor poder de regulación al Estado sobre los grupos financieros.

Se han implementado también dos medidas importantes para una mejor gestión e inversión pública. Por un lado, Kicillof y el ministro de Planificación Federal han presentado el programa Pro.Cre.Ar de créditos para la vivienda y la obra pública municipal, con el que el gobierno argentino espera llegar a fines de 2013 con una inyección de más de 40.000 millones de pesos para reactivar la construcción y recuperar el empleo. Por otro lado, se ha creado el Registro de Subsidios e Incentivos, conformado por el padrón de beneficiarios de subsidios de programas y planes de promoción productiva, con excepción de los programas sociales implementados en el área del Ministerio de Desarrollo Social. Si bien cada ministerio conservará la potestad de fijar su política de subsidios, será contralada por la Subsecretaría de Coordinación Económica y Competitividad. Esta subsecretaría, que depende de Kicillof, será la autoridad de aplicación y permitirá potenciar las políticas y la eficiencia del aparato estatal. En sus propias palabras, «la intervención del Estado en la planificación de la economía debe ser inteligente y para eso se requiere un control. El registro no tiene fines estadísticos, sino que será una herramienta que también utilizarán los distintos organismos del Estado» (Página 12, 15/11/2012). Tal y como se plantea en los fundamentos del decreto, «la experiencia acumulada desde el año 2003 revela la necesidad de mejorar y profundizar en las acciones del Estado nacional en cuanto a la planificación del desarrollo económico, actuando sobre el diseño, la elaboración y la propuesta de lineamientos estratégicos para la programación de la política económica (...). A tal fin, corresponde optimizar las políticas económicas y productivas aumentando el grado de eficacia en la utilización de los recursos públicos, con el objetivo de lograr una acción coherente y eficiente del conjunto de medidas de política pública».

Podemos decir, para concluir, que el estallido de la crisis internacional volvió a poner en evidencia las falencias del pensamiento económico dominante. La incapacidad de las teorías ortodoxas para abordar las causas de la crisis y la incapacidad de las políticas de austeridad para salir de ella ponen en evidencia la necesidad de superar el modelo económico, social y político del neoliberalismo. Si el liberalismo económico de Adam Smith 
ofrecía una alternativa capitalista al Estado absolutista y a la sociedad feudal, el neoliberalismo del siglo $\mathrm{xx}$ es una reacción conservadora contra el Estado keynesiano y la sociedad del bienestar. Las políticas de austeridad están dirigidas a los recursos y capacidades del Estado y a los salarios de los trabajadores, y no a las transferencias multimillonarias que se han hecho a los grupos financieros. Con ello se han sustraído de la economía real enormes recursos que minan el bienestar de la población y la demanda agregada en tanto que palanca de crecimiento económico y de generación de empleo. De este modo, los países entran en números rojos y, en lugar de recaudar más a través de impuestos a las altas rentas $y$ al sector financiero, deben hacer frente a los condicionamientos de ajuste del Fondo Monetario Internacional y del Banco Central Europeo, así como a las crecientes tasas de interés, de forma que contraen nueva deuda. Todo ello explica en gran parte que Europa no solo esté estancada económicamente desde hace un año, sino que además, según los últimos datos del Eurostat, el espacio europeo haya terminado el año 2012 en recesión.

Rafael Böcker Zavaro
El enigma del capital y las crisis del capitalismo

David Harvey

2012. Madrid: Ediciones Akal

El precio de la desigualdad. El 1\% de la población tiene lo que el $99 \%$ necesita

Joseph E. Stiglitz

2012. Madrid: Taurus

España destino tercer mundo. Endeudados, sin fábricas, sin empleos y atrapados por el corralito Ramon Muñoz 2012. Bilbao: Deusto

La torre de la arrogancia. Políticas de mercados después de la tormenta

Xosé Carlos Arias y Antón Costas 2011. Barcelona: Ariel

Esta vez es distinto: ocho siglos de necedad financiera

Carmen M. Reinhart y Kenneth S. Rogoff

2011. México: Fondo de Cultura Económica

\section{Austeridad y neoliberalismo}

La medicina de la austeridad compulsiva, basada en recortes arbitrarios de gastos sociales para reducir la deuda y en devaluaciones internas de salarios para ganar competitividad, tiene como efecto un incremento enorme de la desigualdad social. Hay, en la actuali- 